
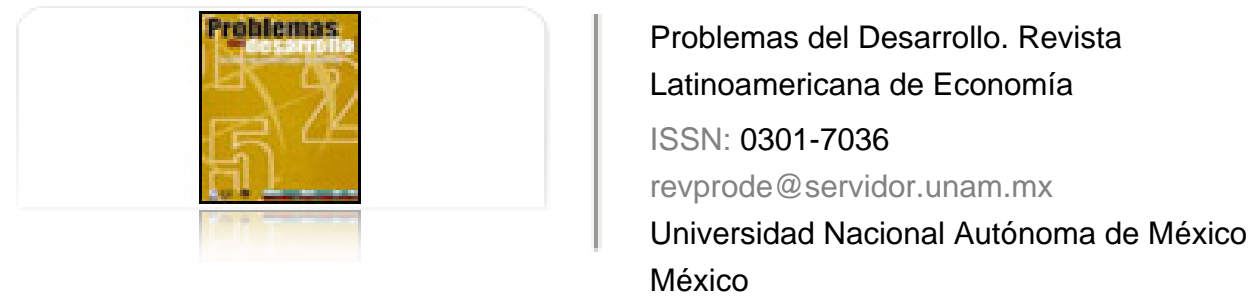

Torres Torres, Felipe

El atraso regional en los procesos globales: la región del plan Puebla-Panamá

Problemas del Desarrollo. Revista Latinoamericana de Economía, vol. 36, núm. 142, julio-septiembre, 2005, pp. 75-100

Universidad Nacional Autónoma de México

Distrito Federal, México

Disponible en: http://www.redalyc.org/articulo.oa?id=11820079005

Cómo citar el artículo

Número completo

- Más información del artículo

Página de la revista en redalyc.org

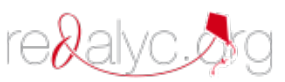

Sistema de Información Científica

Red de Revistas Científicas de América Latina, el Caribe, España y Portugal Proyecto académico sin fines de lucro, desarrollado bajo la iniciativa de acceso abierto 


\section{EL ATRASO REGIONAL EN LOS PROCESOS GLOBALES: la Región del Plan Puebla-Panamá}

\section{Felipe Torres Torres*}

Fecha de recepción: 11 de febrero de 2005. Fecha de aceptación: 17 de agosto de 2005.

\section{Resumen}

Este artículo pretende ubicar por qué las regiones de mayor atraso económico y social del país dificilmente pueden obtener ventajas de los nuevos procesos de desarrollo según las dinámicas de la economía mundial. Resaltamos cómo los proyectos de desarrollo regional surgidos de la planeación gubernamental encuentran, en el contexto de la competencia territorial global, limitaciones para atraer capitales externos. El planteamiento es que las re-giones atrasadas, como el sur-sureste de México, junto con el área centroamericana, las cuales conforman el espectro territorial de influencia del Plan Puebla-Panamá, no han logrado consolidar grupos de capital local, infraestructura o mercados de consumo que les permita aprovechar las ventajas para el desarrollo regional de los flujos de inversión externa.

Palabras clave: desarrollo regional, planeación tegional, inversión externa, dinámicas territoriales, globalización, Plan Puebla-Panamá.

\section{Abstract}

This article tries to establish the reasons why the country's most economically and socially backward regions have difficulty finding advantages in the new development processes, according to the dynamics of the world economy. We note how the regional development projects arising from government planning, in the context of global territorial competition, have limitations in attracting foreign capital. The thesis here is that the backward regions such as Mexico's south-southeast, alongside the Central American area, constituting the Plan Puebla-Panama's territorial spectrum of influence, have not managed to consolidate groups of local capital, infrastructure or consumer markets that would enable them to benefit from the advantages of foreign investment flows for regional development.

Keywords: regional development, regional planning, foreign investment, territorial dynamics, globalization, Plan Puebla-Panama.

* Investigador titular del Instituto de Investigaciones Económicas, UNAM. Correo electrónico: felipet@servidor.unam.mx 


\section{Résumé}

Cet article prétend expliquer pourquoi les régions ayant un retard économique et social du pays peuvent difficilement obtenir des avantages des nouveaux processus de développement selon les dynamiques de l'économie mondiale. On souligne comment, dans le contexte de la concurrence territoriale globale, les projets de développement régional qui ont surgit de la planification gouvernementale trouvent des limitations pour attirer des capitaux externes. La proposition étant que les régions en retard, comme le sud/sud-est du Mexique ainsi que la zone centraméricaine (qui conforment le spectre territorial d'influence du Plan Puebla-Panama), n'ont pas réussi à consolider des groupes de capital local, d'infrastructure ou des marchés de consommation qui leur permettraient de profiter des avantages pour le développement régional des flux d'investissement externe.

Mots clés: développement régional, planification régionale, investissement externe, dynamiques territoriales, globalisation, Plan Puebla-Panama.

\section{Resumo}

Este artigo tenta exprimir por que as regiões de maior atraso económico e social do pais com difuldade podem obter ventagens dos novos processos de desenvolvimento segundo as dinâmicas da economia mundial. Enfatizamos como os projetos de desnvolvimento regional que surgiram do planejamento do governo encontram, no contexto da competência territorial global, limitações para atrair capitais externos. O planejamento é que as regiões com atraso como o sul-suleste do México, além da área da Centro-América, as quais conformam o espetro territorial de influência do Plano Puebla-Panamá, ainda não consolidaram grupos de capital local, infra-estrutura ou mercados de consumo que permita-lhes aproveitar as ventagens para o desenvolvimento regional dos fluxos de investimento externo.

Palavras chave: desenvolvimento regional, planejamento regional, investimento externo, dinâmicas territoriais, globalização, Plano Puebla-Panamá. 


\section{Introducción}

$\mathrm{D}$

espués de algunas décadas de ausencia, en el gobierno del presidente Fox resurge la planeación regional como parte estratégica de la política económica. Ésta contiene diversos planes gubernamentales de orientación territorial, los cuales se diferencian de aquellos que en el pasado concibieron al desarrollo regional a partir de la perspectiva sectorial y no de los equilibrios en el desarrollo de las regiones. Lo que se busca ahora es la promoción activa hacia el capital interno y externo para generar procesos económicos vinculados con objetivos de desarrollo local y adecuados al entorno internacional, para que generen procesos de inversión mediante las ventajas de capital humano y en recursos productivos que puedan ofrecer las regiones.

Sin embargo, la necesidad de aplicar estrategias concebidas a partir del entorno complejo del desarrollo global en regiones con alta marginación enfrenta la dificultad de que las regiones pobres, como es el caso de los estados que conforman la zona sur y sureste del país, considerados por el Plan Puebla-Panamá (Guerrero, Oaxaca, Chiapas, Puebla, Veracruz, Tabasco, Campeche, Quintana Roo y Yucatán) y del área centroamericana (Guatemala, Belice, El Salvador, Honduras, Nicaragua, Costa Rica y Panamá) no han generado procesos económicos locales lo suficientemente fuertes para desarrollar mercados, infraestructura, grupos de capital, experiencia y competitividad de su capital humano, en los cuales se pueda apalancar el capital foráneo y, sobre esa base, otorgar certeza a los procesos globales de alta complejidad tecnológica, interesados en desarrollar regiones altamente competitivas.

Dentro de las estrategias de esa nueva consideración del territorio y las regiones en la política económica de México surgió el Plan Puebla-Panamá (PPP). Éste se ha propuesto como objetivos centrales abatir la pobreza y ayudar a mejorar los niveles de convergencia de la región sur-sureste (S-SE), en complementariedad con los países del área centroamericana también considerados. La zona mexicana del PPP comprende aquellos estados que, por diferentes circunstancias, han mantenido rezagos de desarrollo con relación al resto del país, además de que su situación de atraso social y escaso desarrollo económico los ubica ahora en la categoría de reservas territoriales de inversión para la globalización y sus capitales.

Independientemente de que el PPP enfrenta diversos retrasos y dificultades para su consolidación, relacionados principalmente con el financiamiento estatal y la lentitud de flujo de las inversiones externas por las crisis que enfrenta el capitalismo mundial, es obvio que con el tiempo, este u otro tipo de plan deberá imponerse. Ello requiere considerar otros factores, usualmente no tomados en cuenta por la planeación regional gubernamental, en cuanto a generar procesos efectivos de desarrollo regional y garantizar el mejoramiento social.

\section{Desararrollo}


Así, para aprovechar integralmente los beneficios territoriales que ofrece un proyecto de desarrollo regional en un contexto de alta competitividad mundial, debe existir un proceso previo de sedimentación económica local que se exprese en infraestructura para el desarrollo y en propiciar que las nuevas inversiones, públicas y privadas, generen sinergias positivas, actúen como detonadores del desarrollo regional y permitan alcanzar objetivos de mejoramiento social. Esta sedimentación económica se refiere al nivel de desarrollo previo que debe tener una región para aprovechar de manera óptima los flujos de inversión externa, lo cual se manifiesta en infraestructura carretera y portuaria, comunicación satelital, ciudades conectadas a servicios financieros, empresas que sirvan como proveedoras en ciertos procesos y puedan integrar cadenas productivas con el capital foráneo, capital humano calificado, además de mano de obra barata y flexible a distintos procesos productivos y también un mercado de consumo con un nivel mínimo en algunos estratos de ingreso. Es decir, deben existir grupos de capital, procesos de crecimiento económico consolidados en el nivel regional, o determinado grado de desarrollo alcanzado, particularmente si se trata de implantar actividades productivas sustentables, orientadas a la explotación de recursos naturales, pero basadas en tecnología de punta y hacia la competitividad mundial.

Ante la ausencia previa de ello, el Estado debería considerar establecer una política de fomento a inversiones, la cual pueda tener continuidad en el tiempo y establecer proyectos como el PPP a diferentes velocidades intrarregionales y sectoriales. Debido a su rezago estructural, provocado en parte por las distorsiones regionales del periodo de economía protegida, la región S-SE y por circunstancias de atraso estructural también el área centroamericana, carecen de esa condición o, en todo caso, presenta una relativa asimetría en lo que se refiere a indicadores de desempeño económico, sociales, infraestructura y capacidad de atracción de capital.

Por ejemplo, los estados de Tabasco y Campeche — gracias a su actividad petrolera-, junto con Yucatán — por su orientación turística y manufacturera—, Puebla con capacidad industrial y Veracruz en servicios comerciales, tienen ventajas evidentes sobre Chiapas, Guerrero, Oaxaca y Quintana Roo, independientemente de la localización estratégica o la posesión de recursos naturales de estos últimos. En Centroamérica existen las mismas asimetrías entre países, pero no pocas diferencias de conjunto respecto de la región mexicana. El empuje de los grupos de capital, local y externo, como garantes del éxito del PPP, resulta también asimétrico y requiere la promoción estatal en diferentes magnitudes.

Por tanto, si el camino es promover el desarrollo en las regiones más deprimidas del país mediante la intervención gubernamental, el Estado debe actuar como gestor activo de inversiones externa, local e internacional, y como activador de la inversión pública en infraestructura, dentro de límites de participación que no desencadenen mayores distorsiones regionales. La promoción de la inversión y la generación de procesos de sedimentación, 
conforman ahora parte de una estrategia que pueden diferenciar a la política económica interna de anteriores modelos de desarrollo regional, los cuales extraían los recursos naturales y humanos de las regiones sin promover procesos de desarrollo sostenido que garantizaran mejores condiciones de vida para la población. En un contexto global, los territorios de reserva - como el PPP — que entran a ese proceso deben crear sus propias dinámicas para garantizar la competitividad mundial de esas regiones. Desde luego que éste no es un medio único de desarrollo; existen otros, entre los cuales destaca la gestión local, con diversas experiencias exitosas. Sin embargo, aquí no intentamos hacer ese contraste, sino ubicar las posibilidades de la nueva gestión gubernamental, específicamente en el marco del PPP, considerando las asimetrías regionales del país, principalmente los diferentes niveles de desarrollo intrarregional que presenta la propia área S-SE y las posibilidades de complementariedad regional que podrían o no existir con respecto de la contraparte centroamericana.

Así, el propósito de este trabajo es mostrar algunos aspectos del atraso socioeconómico en el cual se encuentra el área donde se pretende aplicar la estrategia de desarrollo regional del PPP, las asimetrías intraregionales de la misma y el ambiente contradictorio que generan los procesos globales en una región donde, si bien se busca la com-plementariedad regional, en realidad, por la similitud de sus estructuras económicas, enfrenta procesos de competencia económico-territorial en su propio entorno, lo cual puede convertir la propuesta en un intento fallido por resolver los desequilibrios regionales del país.

\section{Algunas características de las asimetrías regionales en la región del $P P P$}

La región del PPP (tanto en su parte mexicana como en la contraparte centroamericana) tiene diferentes niveles de desarrollo, lo mismo que una presencia desigual en su estructura de capital local. Por tanto, la promoción y gestión intrarregional por medio de la planeación gubernamental requiere de distintas estrategias, algunas claramente vinculadas con un criterio exógeno (internacional) y otras que deben partir de la participación o gestión casi exclusiva del Estado. Entre estas últimas destacan las relacionadas directamente con el ataque a la pobreza y otras más que se vinculan con la inversión pública para el desarrollo de infraestructura, la atracción de inversión hacia ramas no convencionales, el mejoramiento competitivo del capital humano local y la movilidad de la población. El diagnóstico de las carencias que obstaculizan el desarrollo económico regional equilibrado resulta fundamental en este proceso de aplicación.

Debido a que el proyecto, por su carácter transterritorial y con distintos ámbitos de competencia gubernamental, enfrenta distintas concepciones de desarrollo regional y formas de estructurar sus propios diagnósticos, nos detenemos principalmente en las características de la región S-SE de México y, de manera más limitada, del área centroamericana.

\section{Desaarrollo}


De acuerdo con un análisis macroeconómico de desempeño económico y social de la zona s-SE, ésta, en su conjunto, tiene una estructura débil; sin embargo, existen menores posibilidades en los estados específicamente sureños: Chiapas, Guerrero y Oaxaca, los cuales participan con menos de la mitad del PIB del área que, a su vez, genera en conjunto $42 \%$ en el PIB nacional (Draisma, 2002). Este comportamiento en los patrones recientes de crecimiento, se infiere, no puede obedecer sólo a factores acumulativos adversos del pasado, sino que conforma una tendencia permanente.

Entre 1993 y 2000, no obstante que la economía mexicana logró crecimientos a una tasa promedio de $3.6 \%$, en los estados del sur, el promedio anual alcanzó apenas $2.1 \%$. Se supone que la variable demográfica es la que más influye en el desfase de la actividad económica. El sur tiene un perfil demográfico más joven que el resto del país, lo cual representa menor cantidad de personas en edad de trabajar, que se complica con la intensidad de las migraciones, junto con la menor participación laboral de las mujeres (27.2\% en el sur frente a $34.7 \%$ en el resto del territorio).

Otros indicadores muestran el mismo nivel de comportamiento adverso que han hecho del S-SE un territorio menos atractivo a la inversión y un obstáculo a la formación de grupos de capital. La tasa de productividad por trabajador en el periodo 1993-2000 aumentó $0.8 \%$ en otras regiones del país, mientras que en el sur decreció en $8.4 \% ; 39 \%$ de la fuerza laboral se desempeña en el sector agrícola, en comparación con 13\% que se registra en todo el territorio. Esta situación tiene implicaciones negativas en el fomento de una estructura económica regional competitiva, así como para canalizar ofertas de los proyectos de alta complejidad tecnológica y organizativa que se gestan actualmente en el mundo.

En suma, los flujos de inversión se orientaron menos a la región s-se y ello contradice la clásica hipótesis de convergencia, la cual sostiene que la inversión será más alta donde la relación capital-trabajo sea menor, debido a la presencia de una mayor rentabilidad. En estas condiciones, la posibilidad de invertir en el S-SE se dificulta inicialmente por los mayores costos de transporte, falta de acceso a infraestructura, protección legal deficiente, costos normativos y corrupción, entre otros (Draisma, op. cit.).

La escasa diversificación de fuentes de financiamiento representa otro obstáculo importante a la formación de grupos de capital en el s-SE y que éstos, a la vez, se conviertan en activadores del desarrollo regional. Más de $90 \%$ del gasto público es de origen federal y alcanzó $36.3 \%$ del PIB en 2000 , frente a $20.2 \%$ de este mismo rubro en el nivel nacional. Los recursos propios de los gobiernos estatales son muy bajos en la región: 5.6\% del gasto público total.

La deficiente productividad laboral provoca el bajo nivel de actividad económica, y de bienes de capital, incluido el humano, así como la falta de inversión. Una forma de revertir las tendencias negativas consistiría en aprovechar las perspectivas de crecimiento de la fuerza laboral activa, como efecto del cambio inmediato de la transición demográfica y la 
creciente participación de las mujeres, junto con un incremento considerable de la inversión en ramas convencionales y no convencionales.

Un fenómeno que puede considerarse favorable, para efectos de la estrategia a que apunta el PPP, es que la descentralización del gasto público está promoviendo una mejor redistribución regional de los recursos en favor de las regiones más pobres, lo cual reduce la capacidad del gobierno federal para orientar la inversión pública hacia una región determinada. Ahora son los gobiernos estatales y municipales los que administran una cantidad cada vez mayor de recursos destinados a fines específicos (Draisma, op. cit.). De otra manera, las expectativas de desarrollo dentro de las estrategias regionales consideradas por el PPP, que buscan mayor competitividad en un ámbito global, pueden ser de poco impacto territorial en áreas que no cuentan con la sedimentación de capitales generados por los procesos de desarrollo económico en el territorio y que marcan dinámicas de atracción de nuevos capitales.

Por ejemplo, el TLCAN y la liberalización comercial no necesariamente han tenido efectos negativos en las dimensiones que originalmente se pensó en la región s-sE, entre otras razones porque las características de la inversión y escasa capacidad de consumo local no les permiten ser partícipes de esas dinámicas. Tampoco los estados que la conforman han podido, por sus bajos niveles de desarrollo, aprovechar las oportunidades, tal como lo hicieron diversas entidades del país que cuentan con otros niveles de sedimentación económica. Es decir, simplemente no existe la posibilidad de lograr mejor nivel de desarrollo para revertir las condiciones sociales adversas en tanto se carezca de los elementos endógenos que puedan actuar como factores de atracción. Los estados del sur no han obtenido provecho del TLCAN porque no estaban preparados para posesionarse de las ventajas del libre comercio en términos de desarrollo, pues no tienen infraestructura suficiente y acceso a los servicios de telecomunicaciones, así como inestabilidad social recurrente y problemas de gobernabilidad que influyen en las decisiones de inversión (Esquivel et al., 2002).

Una explicación de la influencia que los procesos previos de sedimentación económica podrían presentar en el aprovechamiento de los proyectos de desarrollo regional con características exógenas es la productividad extremadamente baja de los trabajadores en la región S-SE. Una baja productividad implica que los trabajadores disponen de bajo nivel de inversión en capital, físico y financiero. A lo que se suman problemas educativos, de estructura, de propiedad de la tierra, falta de infraestructura física y financiera. Por su parte, la violencia y el narcotráfico no sólo están relacionados con importantes temas delictivos y de derechos humanos, sino que actúan como desincentivos para la inversión y el crecimiento económico de la zona (Esquivel, op. cit.).

Estas limitaciones no necesariamente impedirían que el área del PPP pueda reencauzar con éxito su desarrollo en el contexto del proyecto regional planteado. Sus estrategias van

\section{Desaarrollo}


encaminadas a mejorar la infraestructura para el transporte y las comunicaciones, la educación, la reforma de la tierra y la estabilidad social para ayudar a promover las inversiones que se requieren en cuanto a acelerar su crecimiento y reducir la pobreza; sin embargo, el rezago aún es considerable y el flujo de inversiones, como activador principal, todavía lento.

Las acciones de desarrollo regional orientadas hacia el nivel — según la consistencia de la sedimentación espacial de los grupos económicos y tomando en cuenta las diferencias intrarregionales y los nichos de inversión ya vinculados desde mucho antes con los procesos globales, como la actividad turística - deben considerar, para el alcance de los objetivos sociales contenidos en las políticas, los factores de producción disponibles en esos estados que son hoy inapreciables, como la tierra y los recursos naturales (bosques y agua). En tal caso, también el tipo de inversión externa y su orientación influyen para actuar como detonantes de un desarrollo regional sostenido, dependiendo de la capacidad de la planeación para seleccionar tipos de inversión. En México, la inversión extranjera directa (IED) se concentra principalmente en la frontera norte y la ciudad de México, donde fluctúa entre 1812 y 4315 dólares per capita; en contraste, en los estados del S-SE, con excepción de Quintana Roo, oscila entre 1 y 122 dólares per capita (Esquivel, op. cit.).

La volatilidad de la inversión es, entonces, un factor por considerar para encaminar procesos de sedimentación que generen un tipo de desarrollo regional sólido en el contexto complejo y competitivo de la globalización, particularmente si se trata de contar con factores de mejoramiento y arraigo del capital humano.

Está comprobado que cuando la IED aumenta, así sea para actividades económicas de corte temporal, la posibilidad de migrar de la población en el estado receptor disminuye significativamente. Sin embargo, es poco probable que un aumento en el tamaño de la inversión del sector público, el cual canaliza principalmente la infraestructura vial y eléctrica de corte temporal, sea una solución para superar el atraso regional en espacios que han carecido de otros componentes que funcionan estructuralmente como atractivo de inversión; incluso, puede ser negativo si la estrategia se encamina a gasto social improductivo usando el ataque a la pobreza como justificación.

\section{Características de la inversión en la región del PPP}

\section{Alcances territoriales}

Promoción y capacidad de gestión son dos aspectos implícitos en las actuales políticas de desarrollo regional, considerando la competencia regional mundial por la atracción de capital para el financiamiento del desarrollo, principalmente en espacios de reserva que apenas se incorporan a estrategias de esa naturaleza. Si medimos la dinámica del PPP en la zona mediante recursos públicos promovidos por el Estado, así sea en su incipiente operación, concluiríamos que se inscribe en las incongruencias de la política económica regio- 
nal que ha caracterizado a la presente administración. Lejos de incrementarse, el financiamiento otorgado por el sector público a la dotación de infraestructura disminuyó de 7 mil millones de pesos al inicio del Plan en 2001 a 860 millones de pesos en 2004 y con expectativas menores para 2005; los proyectos más representativos en desarrollo de infraestructura que se requieren para fomentar políticas de atracción de inversión se encuentran en franco atraso.

Si se mide por el lado de la gestión de capital externo, también exhibiría el fracaso del Estado en la nueva gestión del desarrollo regional, tanto por la escasa diversificación de fuentes de financiamiento como por la recurrencia a organismos financieros que no se han preocupado por la gestión del desarrollo regional y, en cambio, han contribuido a incrementar la dependencia externa de la economía mexicana y las asimetrías del desarrollo regional por medio del endeudamiento externo. Dada la persistencia de la crisis de la economía mexicana y la falta de credibilidad en la conducción de la administración pública actual, los capitales locales tampoco concurren como se esperaba, por lo tanto, el éxito de la gestión en el exterior para atraer capitales diversificados es todavía insuficiente.

El financiamiento del PPP ha correspondido hasta ahora a los gobiernos de México, Guatemala, El Salvador, Honduras, Nicaragua, Costa Rica y Panamá. El Banco Interamericano de Desarrollo (BID) aporta fondos y funciona como aparato administrativo para la promoción y canalización de inversiones. Otras fuentes son - aunque algunas de ellas ya operaban en la región antes del PPP — el gobierno de España y el Banco Japonés para la Cooperación Internacional, junto con la Unión Europea, el Banco Mundial y el Fondo para el Medio Ambiente de la onU, que administra el Corredor Biológico Mesoamericano, anexado a la estrategia de desarrollo propuesta por el PPP.

Las empresas privadas registran una presencia todavía débil; sin embargo, las más prometedoras son de capital extranjero, principalmente estadounidense, y consideran la región del PPP como su área de influencia; por ejemplo, la productora de papel Paper y Boise Cascade invierte ya en Chiapas y Oaxaca mediante la compra de terrenos, con la finalidad de convertirlos en plantaciones de madera.

En cuanto a generación de energía eléctrica mediante sistema hidroeléctrico — un aspecto clave de las inversiones y de la dotación de infraestructura al PPP-, la empresa española Endesa es la principal inversionista, pero además empuja hacia la privatización de la energía, lo cual en parte explica las presiones del capital para la reforma eléctrica mexicana. También están presentes las norteamericanas Hanken Energy, Duke Energy, Harza y Applied Energy Services, las cuales invierten en la construcción de presas hidroeléctricas desde México hasta Panamá.

Entre los capitales nacionales, el Grupo Pulsar, dentro de la línea de la biotecnología, invierte, antes de la operación del PPP, en plantaciones del estado de Chiapas para investigar en la producción de plantas transgénicas. Ya dentro de las dinámicas del PPP se han

\section{Desaarrollo}




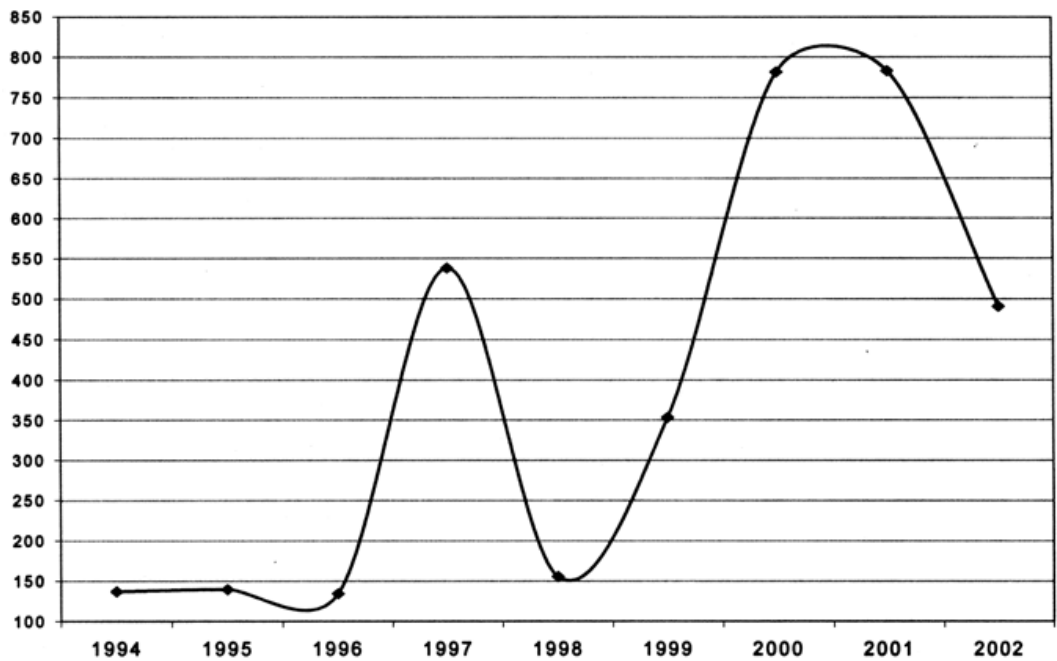

Gráfica 1. Inversión extranjera directa en la región sur-sureste de México (millones de dólares). Fuente: elaboración propia con base en datos del Cuadro 1. Construcción de Teodoro Aguilar.

incorporado otros grupos de empresas tanto nacionales como internacionales; entre ellos, Tribasa, Caros, GAN, ICA, Inbursa, Texas Conection, Internacional Shiphoding Corporation, Monsanto Shell, Dow Chemical, Exxon y Hutchinson Holdings.

Las empresas que mejor posicionamiento han logrado son las encargadas de la infraestructura, particularmente relacionadas con la construcción, reparación y modernización de carreteras, puertos y aeropuertos. En Centroamérica, la empresa estadounidense Prescott and Follet obtuvo un contrato de 25 años para la privatización y modernización de los puertos Bilwi y Cabezas en la costa del Atlántico de Nicaragua, el cual incluye la construcción de carreteras de acceso (Sepúlveda, 2002).

Sin embargo, más allá de la presencia incipiente de capitales externos que podrían dar viabilidad al PPP, lo cierto es que la región en su conjunto, tiene niveles de sedimentación económica muy bajos, lo cual incluye la conformación de mercados regionales incipientes y una gran dispersión regional que se convierten en obstáculos para encauzar procesos endógenos y consolidar un desarrollo regional sostenible, encaminado a contrarrestar los viejos esquemas de extracción de recursos y enfrentar nuevos fenómenos derivados de un desarrollo territorialmente asimétrico del país, como la marginación y el incremento de las migraciones.

Un análisis sectorial de la presencia de capitales da cuenta de esas dificultades. De siete ramas de la producción consideradas (agropecuaria, minería y extracción de petróleo, industria manufacturera, construcción, comercio, servicios, transporte y comunicaciones) sólo Puebla, Quintana Roo, Veracruz y Yucatán registran una presencia de empresas relativamente importante en el nivel nacional; en el caso de Quintana Roo, que concentra la 


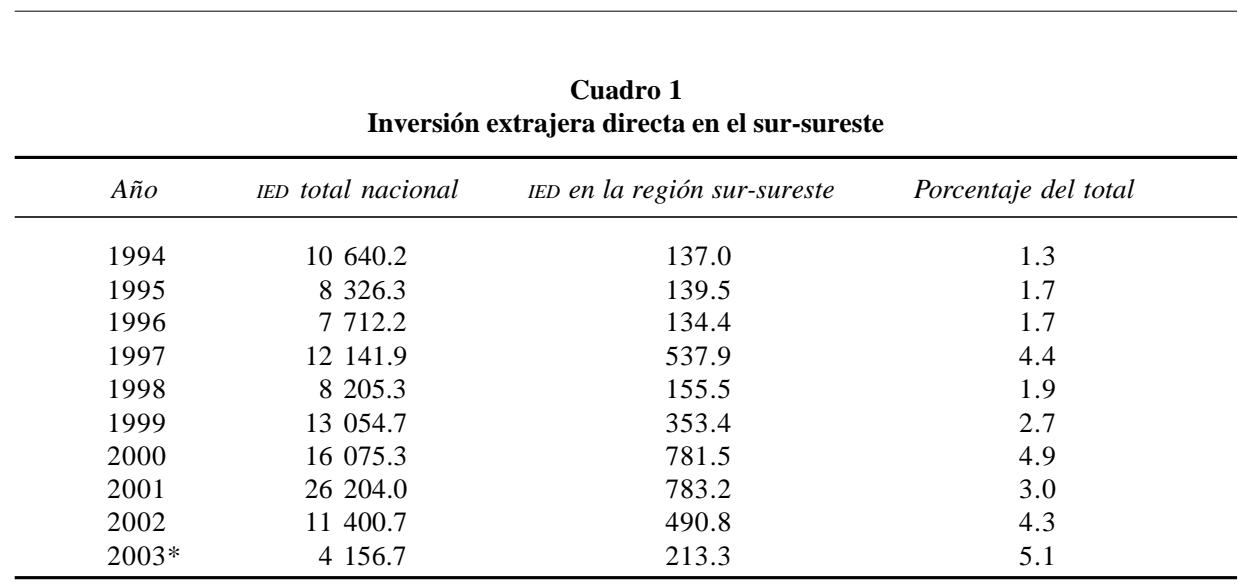

* Enero-junio.

Fuente: elaboración propia con base en datos de INEGI, BIE (Banco de Información Económica), 2003.

proporción más alta, 5.3\%, obedece a la localización de empresas en el comercio y los servicios, las cuales surgieron gracias al desarrollo turístico observado en las tres últimas décadas, pero que podrían entrar en fase de agotamiento, tanto por la competencia mundial como por los eventos naturales que azotan la región y destruyen infraestructura. De cualquier manera, éste es un caso típico de desarrollo regional asimétrico en México y uno de los nichos regionales que más interesan a los proyectos globales, lo cual podría inducir a nuevas distorsiones regionales en el área del PPP.

En el nivel intrarregional las diferencias entre los estados son más notorias: más de $80 \%$ de las empresas de la zona se localizan en las mismas provincias señaladas, las cuales presentan también la mayor diversificación por tipo de actividad. En el caso de Guerrero, Oaxaca, Chiapas y Tabasco, la mayor parte de sus empresas se desempeñan en actividades primarias o, bien, en el comercio y los servicios; en cambio, las de actividades industriales tienen una presencia débil; en todo caso se trata de empresas vinculadas con el comercio y los servicios. Las compañías manufactureras, de aparición reciente en algunos estados, son volátiles y las petroleras han operado más bien como distorsionadoras territoriales al atraer migrantes de otras zonas del país, sin incidir en la diversificación productiva local. Esta situación implica que para generar procesos competitivos asociados a los objetivos del PPP, deberán ampliarse las estrategias de gestión del desarrollo y trascender el carácter hasta ahora estático de los territorios en reserva, lo cual evitaría que este tipo de estrategias se orientara hacia nichos territoriales específicos de México y Centroamérica que indujeran distorsiones territoriales más graves que en el pasado, sin alcanzar los objetivos de combate a la pobreza y la desigualdad regional.

Las asimetrías interregionales también se presentan en el nivel interestatal. Los estados con más débil presencia empresarial son los que registran la mayor concentración territorial de establecimientos por municipio, que en muchos casos se ubican en las principales

\section{Desaarrollo}


ciudades de cada estado. Ello representa otro de los grandes obstáculos que deberán enfrentarse en lo que corresponde a conseguir un mejor equilibrio territorial en espacios que ya de por sí presentan alta marginación y elevados niveles de migración.

De no existir un mecanismo estatal que resuelva a futuro el bajo nivel de sedimentación económica regional, así como las distorsiones territoriales que presenta el desarrollo, es poco probable que el PPP alcance los niveles de convergencia esperados. En todo caso, la estrategia de incorporación de territorios en reserva, como lo es la región s-SE, sólo quedaría en ciertos fragmentos o enclaves territoriales, insuficiente para abatir el atraso y la marginación. Un repaso a los flujos de inversión extranjera en la región parece marcar esa tendencia negativa.

La región S-SE participó apenas con 3.6\% en la recepción de IED en el nivel nacional durante el periodo 1999-2003. Esto significa que la gestión derivada del PPP no mostró señales positivas para atraer inversión, al menos como se esperaba en este primer momento, por lo que el Estado deberá participar más con inversiones públicas y, al mismo tiempo, mejorar los mecanismos de promoción externa, tendientes a un esquema endógeno de desarrollo regional.

La participación por estado es más desequilibrada. Sólo Puebla, con $2.5 \%$ de participación nacional en ese rubro, presentó algún grado de significancia. Quintana Roo y Yucatán lograron captar $0.4 \%$ cada uno, a pesar de las dinámicas que generan la actividad turística y la maquila en un caso y otro. El resto de los estados tiene un nivel de captación francamente nulo, lo cual representa que el financiamiento al PPP no estaría dado inicialmente por factores externos, por lo que se requiere alentar un modelo endógeno en el cual concurran los capitales nacionales, adecuando sus estrategias de inversión a una dimensión global regional.

Un comportamiento similar observamos en las empresas productivas y la naturaleza de las mismas. A pesar de que la región está conformada por nueve estados que equivale, en concentración, a poco más de la tercera parte de la población mexicana y a casi la mitad de la superficie del país, apenas cuenta con la presencia de poco menos de 18\% de los establecimientos. Entre ellos, aparecen nuevamente Quintana Roo, Yucatán, Veracruz y Puebla como los únicos que tienen alguna representatividad importante en el territorio nacional, además de que por sí solos concentran cerca de $80 \%$ del total de los establecimientos en el nivel regional.

La presencia regional de empresas en el nivel sectorial muestra también un marcado desequilibrio. Los estados con mayores desventajas regionales registran el predominio de empresas del sector agropecuario y de actividades extractivas; en cambio, los giros de manufacturas, comercio y servicios, que son más dinámicos en inversión y empleo, se localizan en los estados que presentan las mayores ventajas. 


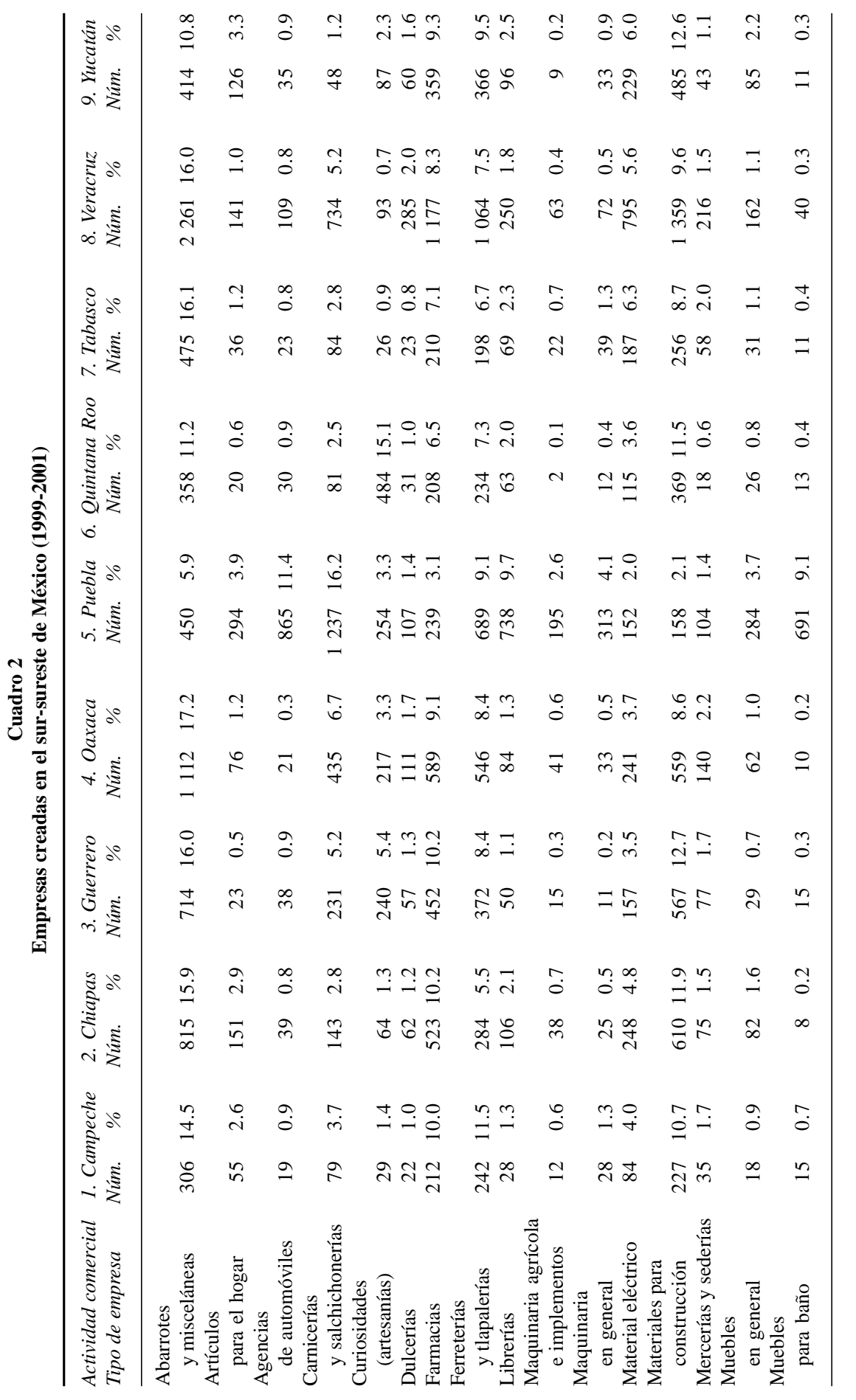




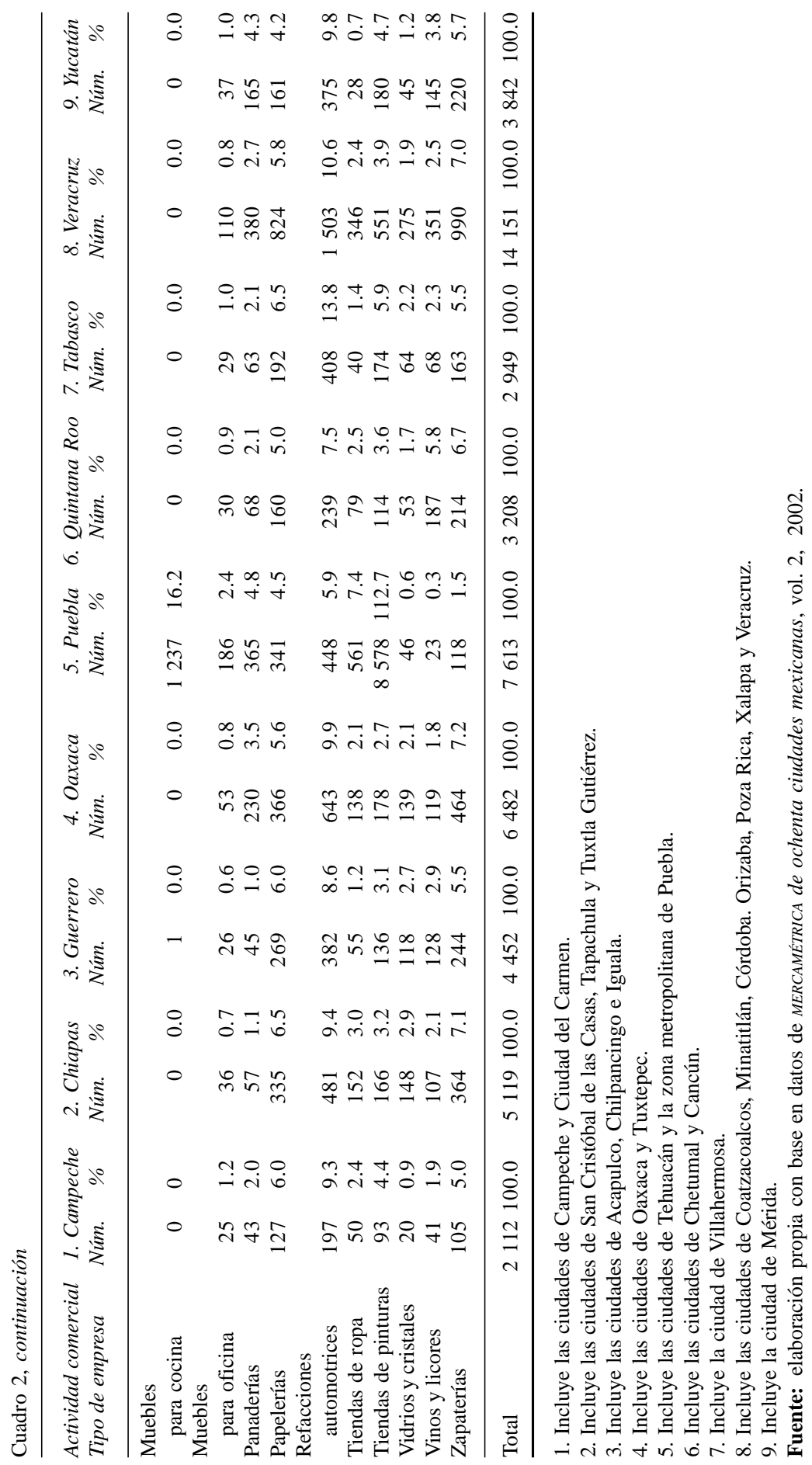




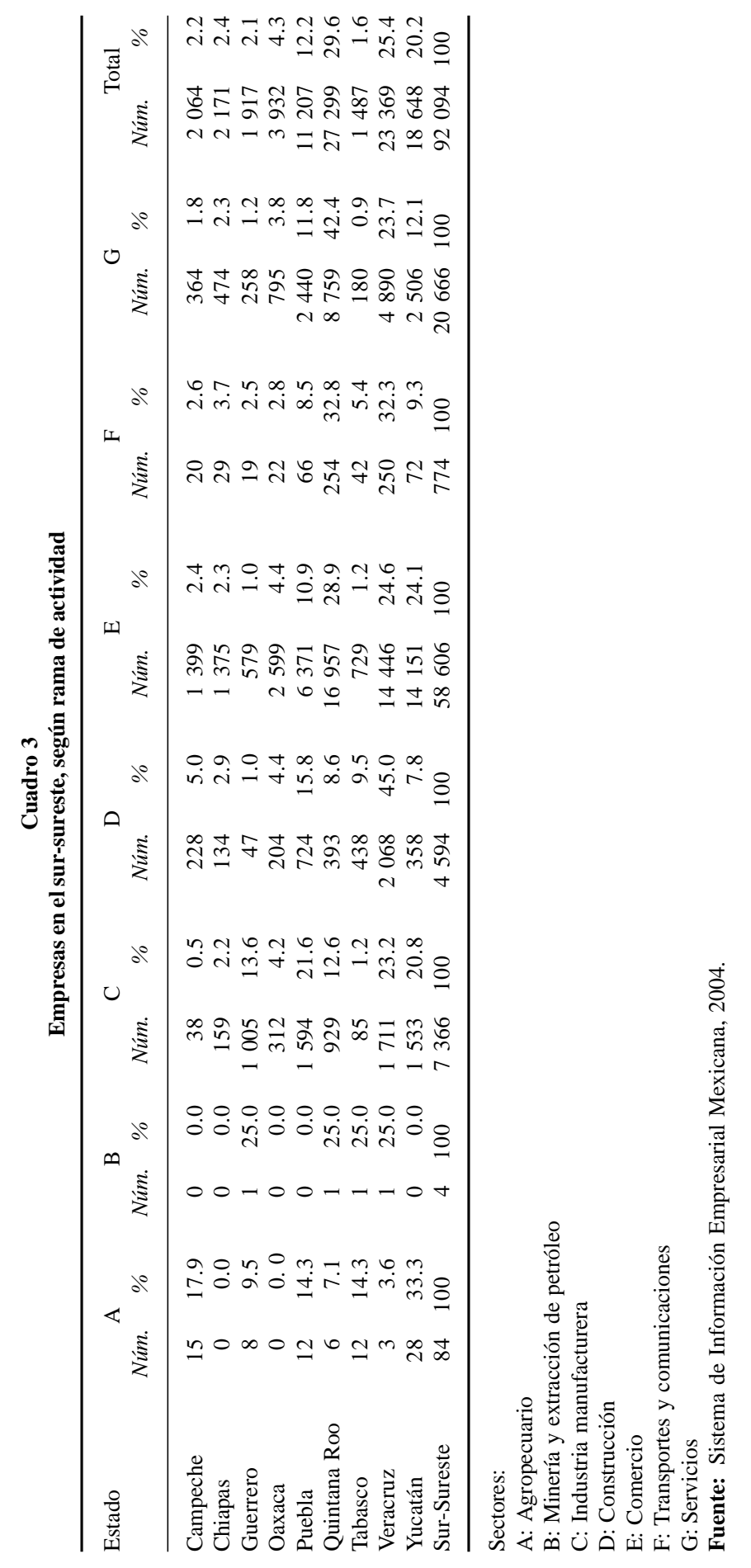




\section{Subíndices de competitividad regional}

Para complementar el análisis acerca de las posibilidades de la región, de lograr en el corto plazo, procesos de sedimentación económica que le permitan generar ventajas en las estrategias del PPP, ${ }^{1}$ alcanzar mayor nivel de convergencia nacional y conformarse como espacio atractivo mundial, recurrimos a la construcción de un índice de competitividad que permita al gobierno mexicano establecer referentes adicionales para emprender acciones en los aspectos más débiles del desarrollo.

1 El índice de competitividad se retomó del trabajo de Teodoro Aguilar citado en la bibliografía. Este corresponde a una forma de clasificar regiones y ubicar aquellas que requieren ser atendidas en rezagos y carencias de infraestructura productiva. El índice importa para definir los indicadores con las cuales se evalúa la capacidad de las regiones, estados o municipios en su grado de competitividad y define las variables que condicionan la capacidad de la región para acceder a servicios que permitan en el corto plazo promover procesos de inversión y mejoramiento de sus condiciones de vida y, en el largo plazo, reducir la brecha del desarrollo territorial existente en el país. El primer paso para la selección y delimitación de las unidades territoriales - por estudiar - consiste en identificar variables que permitan calificar la ubicación de cada una de ellas en competitividad (un grave problema metodológico en la construcción de un índice de competitividad radica en la falta de un criterio general para seleccionar los indicadores relevantes, en la medida en que no existe una relación generalmente aceptada de los indicadores específicos). Los siete factores de competitividad considerados en este caso para la medición y evaluación de los estados mexicanos son: a) educación de la población; $b$ ) carreteras; c) porcentaje de la PEA ocupada; $d$ ) especialización de la fuerza de trabajo; e) PIB monetario y per capita; $f$ ) grado de urbanización; g) migración neta.

La primera variable analiza la educación. En este caso tomamos en cuenta el índice de alfabetismo y la educación promedio de la población, medido en años escolares. Esta variable contribuye a determinar la posición de las microrregiones en cuanto a disponibilidad de mano de obra calificada; además, el capital humano, medido por tasas de alfabetismo, tiene un efecto importante en las posibilidades de crecimiento y sedimentación económica de la región. Estos siete factores son variables que miden la existencia de rezago de las entidades de la región S $\sim$ SE. Una vez calculados o estandarizados los siete indicadores o subíndices de competitividad, construimos una medida resumen que expresa el nivel competitivo. El índice permite establecer un ordenamiento entre las unidades de observación, es decir, los estados o municipios en su caso, reflejando en forma concisa y simple la información contenida en los diferentes indicadores o factores de competitividad, y que sea comparable con los otros indicadores, para que sea posible catalogarlos y ordenarlos en forma ascendente o descendente. La competitividad global es un índice compuesto que se obtiene del promedio de los índices o subíndices calculados, expresados de la siguiente manera:

donde:

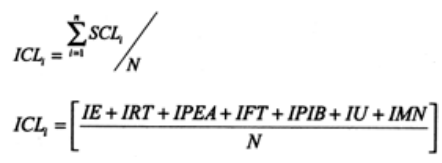

ICL $_{\mathrm{i}}$ es el índice de competitividad local en la comunidad i ésima.

$\mathrm{SCL}_{\mathrm{i}}$ es el subíndice correspondiente a cada uno de los siete factores de competitividad catalogados y definidos en la metodología.

$\mathrm{N}$ es el número de índices o subíndices por categoría para cada comunidad, en este caso 7.

En la construcción del índice de competitividad no empleamos ponderaciones, ya que éstas obedecen, en términos estadísticos, al peso que cada variable aporta al total de los datos; sin embargo, 
Como se desprende de la construcción del índice, existe una relación directa entre el nivel de competitividad y el desarrollo económico de una localidad, lo cual determina que la competitividad afecte directamente al nivel de desarrollo y la marginación; es decir, las localidades que presentan mayor competitividad tienden a ser las de menor marginación y mayor desarrollo económico y social. Por ello, no puede esperarse que los servicios o la industria se instalen en las regiones pobres, si éstas no cuentan por lo menos con servicios educativos y de infraestructura equiparables a los estados más desarrollados, lo cual a largo plazo se convierte en altos grados de divergencia y retrasa las posibilidades de aumentar el grado de sedimentación económica como factor de desarrollo en las condiciones de la globalización.

Para el caso de la región, más allá de las similitudes con Centroamérica —que por razones de información y diferencias administrativas no podemos homologar por ahoraencontramos que excepto el estado de Quintana Roo, el cual es competitivo debido al desarrollo turístico de nivel internacional, el resto se clasifica como poco competitivos o no competitivos en el ámbito nacional, lo que evidencia la necesidad de realizar grandes esfuerzos de inversión más allá de las dinámicas tradicionales del conjunto de los estados. En tal caso, no resulta suficiente la alta disponibilidad de mano de obra o la abundancia de recursos naturales, sino un amplio despliegue de inversión en infraestructura de nivel mundial para posesionar al territorio en la competencia, junto con la atracción de capitales de alta tecnología y el redireccionamiento del desarrollo con un enfoque sustentable.

Un rasgo sobresaliente al iniciar el nuevo milenio es la importancia que ha cobrado la competitividad territorial como base del desarrollo económico. Por ello, los gobiernos buscan promover esta ventaja como estrategia para el mejoramiento de su producción interna, requisito para el aumento en sus exportaciones y garante del equilibrio social en cuanto a generación de empleos.

En la globalización, los países y las regiones tienden a especializarse en ciertas actividades económicas dentro de las cuales pueden ser competitivos o, bien, presentar condi-

como las variables se encuentran estandarizadas y su valor oscila entre 0 y 1 , lo más que pueden aportar al total es uno. Como lo ideal sería que todas tuvieran valor de 1 entonces, en teoría, todas adquieren el mismo peso en el índice, por lo tanto, no puede ser índice compuesto, sino simple. Con los valores de los subíndices o factores de competitividad se construye el índice de competitividad estatal, el cual representa la media de los subíndices o factores de competitividad. Una vez evaluados y obtenido el valor numérico, los colocamos de mayor a menor para ubicarlos con respecto de su competitividad, de tal forma que el más competitivo aparece en primer lugar y así sucesivamente. Los criterios para determinar el grado de competitividad son los siguientes: si $X$ es el dato observado, éste se encuentra en cierto intervalo y a cada uno de éstos le corresponde un grado en particular definido de la siguiente manera:

Si $0<\mathrm{X}<0.39$, entonces $\mathrm{X}$ es "no competitivo".

Si $0.40<\mathrm{X}<0.54$, entonces $\mathrm{X}$ es "poco competitivo".

Si $0.55<\mathrm{X}<1$, entonces $\mathrm{X}$ es "competitivo".

\section{Desaarrollo}


FELIPE TORRES TORRES

Cuadro 4

Índices o subíndices de competitividad

\begin{tabular}{|c|c|c|c|c|c|c|c|}
\hline & Educación & Carreteras & PEAO & Especialización & $P I B$ & Urbanización & Migración \\
\hline Aguascalientes & 0.79 & 0.36 & 0.86 & 0.82 & 0.19 & 0.36 & 0.48 \\
\hline Baja California & 0.86 & 0.18 & 0.99 & 0.90 & 0.27 & 0.43 & 0.77 \\
\hline Baja California Sur & 0.85 & 0.55 & 1.00 & 0.61 & 0.19 & 0.32 & 0.71 \\
\hline Campeche & 0.50 & 0.71 & 0.88 & 0.42 & 0.27 & 0.29 & 0.37 \\
\hline Coahuila & 0.87 & 0.24 & 0.92 & 0.95 & 0.27 & 0.41 & 0.33 \\
\hline Colima & 0.69 & 0.41 & 0.99 & 0.61 & 0.13 & 0.37 & 0.44 \\
\hline Chiapas & 0.00 & 0.21 & 0.97 & 0.00 & 0.03 & 0.19 & 0.24 \\
\hline Chihuahua & 0.78 & 0.24 & 0.93 & 0.87 & 0.33 & 0.38 & 0.52 \\
\hline Distrito Federal & 1.00 & 0.09 & 1.00 & 0.97 & 1.00 & 1.00 & 0.00 \\
\hline Durango & 0.73 & 0.37 & 0.88 & 0.46 & 0.11 & 0.02 & 0.19 \\
\hline Guanajuato & 0.43 & 0.25 & 0.85 & 0.59 & 0.12 & 0.31 & 0.35 \\
\hline Guerrero & 0.10 & 0.21 & 0.90 & 0.43 & 0.05 & 0.25 & 0.13 \\
\hline Hidalgo & 0.36 & 0.34 & 0.78 & 0.40 & 0.07 & 0.24 & 0.34 \\
\hline Jalisco & 0.71 & 0.19 & 1.00 & 0.82 & 0.27 & 0.38 & 0.33 \\
\hline México & 0.76 & 0.31 & 0.93 & 0.45 & 0.32 & 0.55 & 0.45 \\
\hline Michoacán & 0.37 & 0.26 & 0.90 & 0.31 & 0.08 & 0.29 & 0.30 \\
\hline Morelos & 0.64 & 0.47 & 0.92 & 0.70 & 0.13 & 0.48 & 0.47 \\
\hline Nayarit & 0.60 & 0.25 & 0.97 & 0.38 & 0.04 & 0.28 & 0.29 \\
\hline Nuevo León & 0.92 & 0.20 & 0.98 & 1.00 & 0.45 & 0.48 & 0.43 \\
\hline Oaxaca & 0.06 & 0.19 & 0.89 & 0.11 & 0.02 & 0.20 & 0.19 \\
\hline Puebla & 0.38 & 0.21 & 0.88 & 0.44 & 0.12 & 0.35 & 0.29 \\
\hline Querétaro & 0.61 & 0.25 & 0.90 & 0.81 & 0.21 & 0.32 & 0.54 \\
\hline Quintana Roo & 0.70 & 0.33 & 0.94 & 0.66 & 0.26 & 0.36 & 1.00 \\
\hline San Luis Potosí & 0.50 & 0.26 & 0.87 & 0.38 & 0.10 & 0.26 & 0.25 \\
\hline Sinaloa & 0.66 & 0.22 & 0.90 & 0.40 & 0.12 & 0.30 & 0.25 \\
\hline Sonora & 0.83 & 0.39 & 0.92 & 0.62 & 0.24 & 0.35 & 0.39 \\
\hline Tabasco & 0.57 & 0.44 & 0.83 & 0.34 & 0.06 & 0.29 & 0.21 \\
\hline Tamaulipas & 0.80 & 0.24 & 0.97 & 0.88 & 0.21 & 0.42 & 0.55 \\
\hline Tlaxcala & 0.67 & 0.51 & 0.90 & 0.64 & 0.03 & 0.45 & 0.41 \\
\hline Veracruz & 0.35 & 0.18 & 0.93 & 0.20 & 0.12 & 0.26 & 0.10 \\
\hline Yucatán & 0.46 & 0.65 & 0.97 & 0.65 & 0.10 & 0.37 & 0.32 \\
\hline Zacatecas & 0.57 & 0.35 & 0.82 & 0.28 & 0.03 & 0.23 & 0.26 \\
\hline Promedio nacional & 0.60 & 0.32 & 0.92 & 0.57 & 0.19 & 0.35 & 0.37 \\
\hline
\end{tabular}

Fuente: elaboración propia con base en datos de INEGI: XI Censo de Población y Vivienda 2000; Encuesta Nacional de Empleo 2003 y Sistema Municipal de Bases de datos 2003. BIE 2003. CONAPO: Sistema Urbano Nacional 2003; Índice de Marginación 1995 y 2000; y Sistema Nacional de Ciudades 2000. Construcción de Teodoro Aguilar.

ciones que le permitan alcanzar mayor probabilidad de éxito en el panorama internacional, ya que estas actividades se convierten en la base exportadora de cada país o región.

Además, la competitividad está asociada directamente con el nivel de desarrollo humano alcanzado por una nación. En este sentido, podemos observar que el nivel de desarrollo de una zona es el resultado de su factor competitivo, el cual depende, a su vez, del comportamiento de una serie de indicadores que dan cuenta de la competitividad alcanzada.

A pesar de que la región s-SE cuenta con una gran cantidad de recursos naturales y de una hipotética mano de obra abundante y barata, en la actualidad no basta con la sola disponibi- 
Cuadro 5

Índice de competitividad estatal

\begin{tabular}{|c|c|c|c|}
\hline Estado & Índice de competitividad & Grado de competitividad & Ubicación \\
\hline Aguascalientes & 0.55 & Competitivo & 9 \\
\hline Baja California & 0.63 & Competitivo & 3 \\
\hline Baja California Sur & 0.61 & Competitivo & 5 \\
\hline Campeche & 0.49 & Poco competitivo & 18 \\
\hline Coahuila & 0.57 & Competitivo & 8 \\
\hline Colima & 0.52 & Poco competitivo & 14 \\
\hline Chiapas & 0.23 & No competitivo & 32 \\
\hline Chihuahua & 0.58 & Competitivo & 7 \\
\hline Distrito Federal & 0.72 & Competitivo & 1 \\
\hline Durango & 0.40 & No competitivo & 22 \\
\hline Guanajuato & 0.41 & Poco competitivo & 19 \\
\hline Guerrero & 0.30 & No competitivo & 30 \\
\hline Hidalgo & 0.36 & No competitivo & 27 \\
\hline Jalisco & 0.53 & Poco competitivo & 13 \\
\hline México & 0.54 & Poco competitivo & 11 \\
\hline Michoacán & 0.36 & No competitivo & 28 \\
\hline Morelos & 0.54 & Poco competitivo & 10 \\
\hline Nayarit & 0.40 & No competitivo & 21 \\
\hline Nuevo León & 0.64 & Competitivo & 2 \\
\hline Oaxaca & 0.24 & No competitivo & 31 \\
\hline Puebla & 0.38 & No competitivo & 24 \\
\hline Querétaro & 0.52 & Poco competitivo & 15 \\
\hline Quintana Roo & 0.61 & Competitivo & 4 \\
\hline San Luis Potosí & 0.37 & No competitivo & 25 \\
\hline Sinaloa & 0.41 & Poco competitivo & 20 \\
\hline Sonora & 0.53 & Poco competitivo & 12 \\
\hline Tabasco & 0.39 & No competitivo & 23 \\
\hline Tamaulipas & 0.58 & Competitivo & 6 \\
\hline Tlaxcala & 0.52 & Poco competitivo & 16 \\
\hline Veracruz & 0.31 & No competitivo & 29 \\
\hline Yucatán & 0.50 & Poco competitivo & 17 \\
\hline Zacatecas & 0.36 & No competitivo & 26 \\
\hline Promedio nacional & 0.47 & & \\
\hline
\end{tabular}

Fuente: elaboración propia a partir de datos del Cuadro 4. Construcción de Teodoro Aguilar.

lidad de estos factores porque en el nivel mundial otras áreas también lo tienen. La competitividad se determina cada día más en función de la capacidad de generar conocimiento (científico y tecnológico) y no de la dotación inicial de capital. Por lo tanto, la competitividad se basa ahora en las ventajas competitivas y no en las comparativas del pasado. Las primeras se generan al interior de las empresas y de las regiones en donde se ubican.

Sin embargo, pareciera que la región s-SE solamente cuenta con ventajas comparativas en cuanto a centros turísticos, ya que es en ellos y las capitales administrativas de los estados donde se observan las mejores condiciones para la sedimentación económica. El resto de la región tiene un atraso económico y social que difícilmente lograría superar si no es con la intervención directa del Estado. 
Desde el punto de vista regional, las desigualdades se expresan como producto de los diferentes niveles de competitividad y por el nivel de satisfactores como alimentación, educación, seguridad pública y salud, entre otros, que permitan incrementar el nivel de vida y de desarrollo humano. En este sentido, plantear que una zona no es competitiva sería hablar de bajo nivel educativo, de la imposibilidad de que la población se incorpore al mercado laboral, de bajos ingresos, de un abandono paulatino de las comunidades por las altas tasas de emigración o de una falta de medios de comunicación y transporte de bienes y personas. En resumen, de la existencia de un gran número de personas y comunidades aisladas y en pobreza extrema.

El análisis de la competitividad municipal muestra una situación adversa en el s-SE. Esto se expresa en la escasa presencia de una red de caminos que permitan comunicar a la comunidad, junto con mano de obra capacitada, pues las empresas tienden a ubicar sus instalaciones en aquellos lugares que les aseguren fuentes de energía, agua, capacitación laboral y, en general, las condiciones para su buen desempeño. Por lo tanto, aquellos sitios que no ofrecen el mínimo de condiciones o infraestructura serán espacios no competitivos que tenderán a ser expulsores de población, al no ofrecer los medios para que sus habitantes tengan buenas condiciones de salud y educación. ${ }^{2}$

En ese sentido, no es extraño que la región s-SE presente el mayor grado de marginación, en tanto no existen las condiciones de desarrollo económico necesarias para que la población mantenga un nivel de vida digno, por lo cual se detecta baja actividad económica y aislamiento de las comunidades como constante. El análisis de competitividad realizado califica a estas entidades en los últimos lugares en el nivel nacional.

Chiapas, Oaxaca, Guerrero y Veracruz son los estados con peores indicadores en ese rubro. Además, en la catalogación de los municipios que conforman esta región, se observa que éstos se ubican en el mismo nivel que las entidades, es decir, la mayoría de ellos se encuentran en el rango de no competitivos; sólo una minoría puede considerarse competitiva.

Del total de los 1334 municipios que conforman el s-SE de México, sólo 44 de ellos se ubican en rango competitivo; 283 son considerados poco competitivos y los restantes 1007 no competitivos. Así, apenas 3.3\% de estos municipios son catalogados como competitivos, contra $75.5 \%$ no competitivo. Este porcentaje coincide con los municipios que se encuentran en pobreza y pobreza extrema.

Los municipios competitivos corresponden a las capitales de los estados, centros turísticos y las zonas petroleras, los cuales, por su gran capacidad de generar riqueza, ocupan

2 Sin embargo, este análisis también podría concluir que el gobierno apuesta a la dotación de infraestructura física (que en realidad es el objetivo principal del PPP) como un requisito y una exigencia a los inversionistas extranjeros de instalar transnacionales, las cuales solamente buscan aprovechar la mano de obra abundante y barata, la gran cantidad de recursos naturales y los bajos costos de los energéticos, tanto petroleros como eléctricos. 
un lugar importante, sin que ello signifique que la riqueza generada se distribuya equitativamente entre la población. Caso atípico es el estado de Tabasco, el cual sólo ubica municipios del centro, donde se encuentra la capital del estado, como competitivos; similar al estado de Chiapas, donde nada más los municipios de Tuxtla Gutiérrez y San Cristóbal de las Casas son catalogados como competitivos, uno de ellos la capital del estado y el otro un importante centro turístico.

En tal caso, podemos concluir que la estructura del capital en el conjunto de la región presenta un comportamiento débil, como reflejo de las políticas de desarrollo regional del pasado que, por su carácter extractivo, no generaron procesos de sedimentación que crearan bases sólidas para un desarrollo endógeno territorialmente equilibrado. En la región se ubican más bien pequeñas y medianas empresas orientadas al comercio y los servicios y la mayoría de ellas se localizan en menos de la mitad de los estados que conforman la región. Además, apenas uno de esos estados resulta competitivo en el nivel nacional, por lo cual los flujos de inversión extranjera son casi nulos para toda la región. Así, ésta todavía dependerá de la participación pública para generar infraestructura y mejoramiento del capital humano que permitan a este territorio de reserva ser competitivo dentro de las estrategias que persigue el capital internacional, pero adecuada al entorno local, que en las condiciones de pobreza y marginación actual no podrá lograrlo. En tal caso, la coordinación efectiva con los países centroamericanos será un factor determinante para el éxito regional del PPP.

\section{La situación de Centroamérica frente a sus perspectivas}

de desarrollo regional en el PPP

La estructura económica del área centroamericana no es diferente a la de los estados que conforman el S-SE de México. Históricamente, ambas delimitaciones territoriales se han ubicado en niveles de desarrollo económico y social similares, además de que los procesos y los tipos de inversión dominantes han correspondido a las típicas economías de enclave; ello ha impedido contar con niveles de sedimentación económica suficientes para aprovechar algunas ventajas de la inversión extranjera en su desarrollo regional y más bien se han mantenido en niveles de empobrecimiento permanentes.

Esto mismo pareciera tender a reproducirse con el PPP. Las dinámicas globales en los cuales se inscribe la estrategia sólo buscan algunos nichos específicos de inversión y aprovechamiento de ventajas territoriales, mientras que los países del área intentan, por su parte, vincularse más a la economía estadounidense mediante tratados particulares —en cuyos mecanismos de cooperación interregional están ausentes y se convierten más en economías competidoras que complementarias en cuanto al desarrollo de mercados locales- y enfrentar la competencia del comercio mundial.

\section{Desaarrollo}


Cuadro 6

Municipios competitivos en el sur-sureste

\begin{tabular}{|c|c|c|c|}
\hline Estado & Municipio & Índice & Grado \\
\hline Campeche & Campeche & 0.67 & Competitivo \\
\hline Campeche & Ciudad del Carmen & 0.61 & Competitivo \\
\hline Chiapas & San Cristóbal de las Casas & 0.57 & Competitivo \\
\hline Chiapas & Tuxtla Gutiérrez & 0.66 & Competitivo \\
\hline Guerrero & Acapulco de Juárez & 0.61 & Competitivo \\
\hline Guerrero & Chilpancingo de los Bravo & 0.56 & Competitivo \\
\hline Guerrero & Iguala de la Independencia & 0.56 & Competitivo \\
\hline Guerrero & José Azueta & 0.55 & Competitivo \\
\hline Oaxaca & Oaxaca de Juárez & 0.68 & Competitivo \\
\hline Oaxaca & Salina Cruz & 0.56 & Competitivo \\
\hline Oaxaca & San Agustín de las Juntas & 0.62 & Competitivo \\
\hline Oaxaca & San Andrés Huayapam & 0.63 & Competitivo \\
\hline Oaxaca & San Antonio de la Cal & 0.59 & Competitivo \\
\hline Oaxaca & San Jacinto Amilpas & 0.66 & Competitivo \\
\hline Oaxaca & Ánimas Trujano & 0.58 & Competitivo \\
\hline Oaxaca & Villa de Etla & 0.56 & Competitivo \\
\hline Oaxaca & San Sebastián Tutla & 0.72 & Competitivo \\
\hline Oaxaca & Santa Cruz Amilpas & 0.65 & Competitivo \\
\hline Oaxaca & Santa Cruz Xoxocotlán & 0.64 & Competitivo \\
\hline Oaxaca & Santa Lucía del Camino & 0.64 & Competitivo \\
\hline Oaxaca & Santa María Atzompa & 0.58 & Competitivo \\
\hline Oaxaca & Santa María del Tule & 0.64 & Competitivo \\
\hline Puebla & Puebla & 0.66 & Competitivo \\
\hline Puebla & San Pedro Cholula & 0.55 & Competitivo \\
\hline Puebla & Tehuacán & 0.56 & Competitivo \\
\hline Quintana Roo & Cozumel & 0.63 & Competitivo \\
\hline Quintana Roo & Isla Mujeres & 0.57 & Competitivo \\
\hline Quintana Roo & Benito Juárez & 0.65 & Competitivo \\
\hline Quintana Roo & Solidaridad & 0.60 & Competitivo \\
\hline Tabasco & Centro & 0.57 & Competitivo \\
\hline Veracruz & Banderilla & 0.59 & Competitivo \\
\hline Veracruz & Boca del Río & 0.68 & Competitivo \\
\hline Veracruz & Camerino Z. Mendoza & 0.55 & Competitivo \\
\hline Veracruz & Coatzacoalcos & 0.60 & Competitivo \\
\hline Veracruz & Córdoba & 0.57 & Competitivo \\
\hline Veracruz & Fortín & 0.55 & Competitivo \\
\hline Veracruz & Ixhuatlancillo & 0.55 & Competitivo \\
\hline Veracruz & Xalapa & 0.66 & Competitivo \\
\hline Veracruz & Orizaba & 0.66 & Competitivo \\
\hline Veracruz & Poza Rica de Hidalgo & 0.65 & Competitivo \\
\hline Veracruz & Río Blanco & 0.60 & Competitivo \\
\hline Veracruz & Veracruz & 0.63 & Competitivo \\
\hline Yucatán & Kanasín & 0.56 & Competitivo \\
\hline Yucatán & Mérida & 0.65 & Competitivo \\
\hline
\end{tabular}

Fuente: construcción propia a partir del Cuadro 4. Construcción de Teodoro Aguilar.

Diversas condiciones del área centroamericana presentes en las perspectivas de negociación a futuro apuntarían a que — por el tamaño de las economías locales, su escasa 
capacidad para integrar procesos productivos más complejos y el tipo de participación que buscan en la economía de Estados Unidos, al margen de las ventajas de cooperación y desarrollo que pudiera representar el PPP en oportunidades de atracción de inversiones globales - el desarrollo regional y la solución de problemas regionales que se busca con ello enfrentaría diversas limitaciones y su potencial indiscutible quedaría nuevamente trunco en los procesos globales.

Centroamérica contaba hacia 2002 con una extensión territorial de 521903 km², 35 millones de habitantes, un intercambio comercial de 35 mil millones de dólares y PIB de 63 mil millones; el comercio interregional superó en 2002 los 3 mil millones, los principales socios comerciales son Estados Unidos con 38.3\% del intercambio; el Mercado Común Centroamericano, 28.1\%; la Unión Europea, $12.9 \%$ y el resto de países del mundo, 20.2\% (SIECA, 2003). Es evidente que su intercambio resulta más diversificado que el de México pero, fuera de las manufacturas, la mayoría de los productos que exporta son similares a los de nuestro país y en algunos, como el café y la carne, son competidores de la región sSE, por lo cual su interés se centra en el mercado estadounidense, que se concretó con la firma de un tratado de libre comercio entre esa nación y las centroamericanas (CAFTA) a finales de 2003.

Tal situación se presenta en un contexto al parecer favorable, en el cual todos los países centroamericanos mantuvieron en 2003 inflaciones menores a 10\%, tipos de cambio estables, fortalecimiento del comercio exterior y aumento de las reservas internacionales. También han realizado avances en reformas económicas, fiscal, monetaria, cambiaria y de desregulación económica, apertura comercial (desgravación arancelaria, eliminación de barreras arancelarias) y la diversificación de relaciones comerciales internacionales, mediante tratados comerciales con México, acuerdos marco para el comercio con otros países, la entrada en vigor del Tratado de Libre Comercio con Estados Unidos y la Unión Aduanera de los países centroamericanos. Estas naciones se encuntran ahora, por otra parte, entre los principales destinos de la inversión de empresas mexicanas en el exterior; alrededor de 3024 millones de dólares, de los cuales 1800 millones se canalizaron a Guatemala (SIECA, 2003).

Esa misma dinámica se observa en el surgimiento de nuevas empresas privadas, la mayoría de ellas externas, aunque también se manifiesta una importante movilidad del capital intrarregional. Se aprecia un cambio notable en Centroamérica en cuanto al desarrollo de empresas de todos los tamaños y en todos los sectores. La labor educativa y la motivación por competir (especialmente para importar y exportar) han dado lugar al surgimiento de empresas de diversas formas. Aun así, gran parte de la economía funciona en el contexto de la informalidad. Esto implica diversos desafíos para consolidar la integración en un contexto de globalización y mayor apertura: en primer lugar, una incorporación acelerada al sector formal, por la vía del establecimiento de un mayor número de

\section{Desaarrollo}


Cuadro 7

Algunos indicadores importantes de Centroamérica

$\begin{array}{lr}\text { Tamaño mercado centroamericano (millones de dólares, 2002) } & 89279.2 \\ \text { Extensión territorial }\left(\mathrm{km}^{2}\right) & 423830 \\ \text { Población (millones de habitantes, 2002 estimado) } & 34.8 \\ \text { PIB regional (millones de dólares, precios corrientes, 2002 estimado) } & 63355.0 \\ \text { PIB por habitante (en millones de dólares anuales, promedio, precios corrientes, año 2001) } & 1886.8 \\ \text { Tasa de inflación de la región (en \%, promedio, año 2002) } & 6.2 \\ \text { Tasas de interés nominales activas/pasivas (en \%, promedio, año 2001) } & 20.7 / 12.4 \\ \text { Salario mínimo nominal (en millones de dólares/mes, promedio, año 2002) } & 158.2 \\ \text { Desempleo abierto (en \% de la PEA, promedio, año 2000) } & 7.4 \\ \text { Exportaciones mercancías generales (millones de dólares, año 2002) } & 7603.9 \\ \text { Importaciones mercancías generales (millones de dólares, año 2002) } & 19278.6 \\ \text { Déficit en balanza comercial (millones de dólares, año 2002) } & -11674.7 \\ \text { Maquila y zona franca (millones de dólares, año 2002, excepto Honduras: 2001) } & 5850.3 \\ \text { Bienes para transformación netos (millones de dólares, año 2002) } & 1852.3 \\ \text { Transferencias corrientes netas (millones de dólares, año 2002, excepto Honduras 2001) } & 5136.9 \\ \text { Deuda externa de la región (millones de dólares, total, año 2001) } & 19704.7 \\ \text { Reservas internacionales netas (millones de dólares, total, año 2002) } & 6749.5\end{array}$

Fuente: elaboración propia de la Consejería Comercial de México (ваNсомехт) en Guatemala, con base en diversas fuentes y principalmente estadística del Consejo Monetario Centroamericano.

empresas de ocupación intensiva en mano de obra; en segundo, la construcción de alianzas entre compañías ubicadas en distintos segmentos de las cadenas de valor que hasta ahora mantienen sólo una visión regional y, tercero, mejorar sustancialmente la capacidad competitiva de las empresas de todos los tamaños, en todos los sectores (Pomareda, 2004).

Más allá de esa situación reciente, se reconoce que Centroamérica ha perdido dinamismo en el avance de los principales indicadores sociales que había logrado hasta la primera mitad de la década de los noventa. Otra perspectiva de análisis concluye que el modo de enfrentar los retos mediante un estilo de "desarrollo hacia fuera", sustentado en la apertura comercial, ha generado pocos beneficios sociales, particularmente en el empleo de la población. Asimismo, el PIB por persona en Centroamérica hace cuarenta años era semejante al de hoy, con excepción de Costa Rica y Panamá (Gutiérrez, 2004).

Esta situación resulta contradictoria teniendo en cuenta las dimensiones de la apertura que las economías centroamericanas han venido formalizando. A partir del año 2000 se han acumulado negociaciones y acuerdos entre naciones del área, junto con la incorporación de nuevos países al proceso de construcción de una zona de libre comercio en la región, procesos bilaterales de negociaciones con terceros países, procesos conjuntos de negociaciones con otros en un acelerado proceso de regionalismo abierto. No obstante, la llamada integración centroamericana se ha visto condicionada por cuatro grandes compromisos internacionales: el TLC con Estados Unidos, el PPP, el Área de Libre Comercio de las Américas y las relaciones con la Organización Mundial de Comercio. El TLC con Estados Unidos ha condicionado la naturaleza de la integración (op. cit.). 


\section{Conclusiones}

La región S-SE de México tiene los mayores niveles de atraso económico y marginación social del país. En la misma situación se encuentra Centroamérica; este conjunto regional busca, con la implantación del PPP, una nueva estrategia que les permita mayor desarrollo regional y mejoramiento social. Sin embargo, su condición de atraso les ha impedido consolidar grupos de capital e infraestructura económica local, de tal manera que puedan adecuarse a las inercias del capital internacional para generar procesos efectivos de desarrollo regional y de sedimentación económica como palanca de desarrollo del área.

Por ello, estrategias de desarrollo regional como el PPP, las cuales apuestan a que sea el capital externo el generador de dinámicas locales para impulsar procesos endógenos de desarrollo regional, tienen limitaciones. Ello en la medida de que la propuesta gubernamental, basada en la promoción de las ventajas de los recursos naturales y la localización estratégica de la región, no es suficiente para la atracción de capitales foráneos y para alcanzar, en el largo plazo, la sedimentación regional de los procesos económicos, estabilidad de la inversión, arraigo de la población y mejoramiento social.

Además, la complementariedad regional, en aras de alcanzar un desarrollo armónico, representa un obstáculo en la práctica. Tanto el s-SE de México como la región centroamericana, por la similitud de sus estructuras económicas, lejos de ser complementarias, son competidoras y ambas buscan aprovechar ventajas coyunturales de los procesos económicos mundiales, por lo cual la cooperación, como base del desarrollo regional, es prácticamente nula.

\section{Bibliografía}

Aguilar, Teodoro, "Competitividad regional y estrategias de desarrollo en el Sur y Sureste de México. Índice para evaluar la competitividad del sur-sureste en el ámbito del Plan Puebla Panamá", tesis doctoral, posgrado en Economía, México, unam, 2005.

Carranza, Alvaro J., “¿Hacia dónde va Centroamérica?", en Revista Centroamericana en la Economía Mundial del Siglo XXI, año 2, Guatemala, Asociación de Investigación y Estudios Sociales, 2004.

Cohen, Isaac, “¿Por qué CAFTA?”, en Revista Centroamericana en la Economía Mundial del Siglo $X X I$, año 2, Guatemala, Asociación de Investigación y Estudios Sociales, 2004.

Draisma, Joast, "La macroeconomía en los estados del sur”, reporte de investigación, Washington, Banco Mundial, 2002.
Esquivel, Gerardo, Daniel Lederman, Miguel Mesmacher y Renata Villoro, “¿Porqué el TLCAN no llegó hasta el Sur de México?", reporte de investigación, Washington, Banco Mundial, 2002.

Fernández, Luis Adolfo, "Incidencias del CAFTA en el modelo de desarrollo económico: el caso de Costa Rica”, en Revista Centroamericana en la Economía Mundial del Siglo XXI, año 2, Guatemala, Asociación de Investigación y Estudios Sociales, 2004.

Gutiérrez, Miguel Arturo, "Consenso de Washington: elementos para replantearse", en Revista Centroamericana en la Economía Mundial del Siglo XXI, año 2, Guatemala, Asociación de Investigación y Estudios Sociales, 2004.

Gutiérrez, Miguel, "Crecimiento, desarrollo y estilos de desarrollo en Centroamérica", en Revista Centroamericana en la Economía Mundial del

\section{Desaarrollo}


Siglo XXI, año 2, Guatemala, Asociación de Investigación y Estudios Sociales, 2004.

Hershberg, Eric, "Hacia un consenso centroamericano. Bases para un modelo de desarrollo equitativo", en Revista Centroamericana en la Economía Mundial del Siglo XXI, año 2, Guatemala, Asociación de Investigación y Estudios Sociales, 2004.

Pomareda, Carlos, "Posible incidencia del CAFTA en el modelo de desarrollo en Centroamérica", en Revista Centroamericana en la Economía Mundial del Siglo XXI, año 2, Guatemala, Asociación de Investigación y Estudios Sociales, 2004.

Sepúlveda Ramírez Leandro, Construcción regional $y$ desarrollo productivo en la economía de la globalidad, Buenos Aires, CEPAL, serie Estudios y Perspectivas, 2001.

Sistema Integración Centroamericana, Informe técnico, Guatemala, 2003. 